\title{
The influence of the electronic navigational charts over maritime services
}

\author{
Valentino Palma \\ Italian Hydrographic Institute, valentino_palma@marina.difesa.it
}

Keywords: e-navigation, nautical cartography, S-100, international hydrographic organization

\begin{abstract}
:
Electronic Navigational Charts (ENCs) are based on an International Hydrographic Organization (IHO) standard called S-57 that from the 90s has represented the main reference for nautical cartographers and for the whole hydrographic community. Considering the technological development over the last 20 years, the need of a new standard capable of standing the pace has emerged. The need has been enhanced by another concept developed by the International Maritime Organization (IMO): the e-navigation. Within the e-navigation framework, the new standard has found not only its own role as "Common Maritime Data Structure" (CMDS) but also a fertile ground over which overcome S-57 limits.

The new standard S-100 will not be just a replacement of S-57, it represents its evolution and an innovative way to manage maritime data. Compliant with the ISO 19100 series and based on the experience gained through the practical usage of S-57, S-100 more challenging goal is to use a single standard for multiple applications. Nautical cartography will be just one of the possible applications of the standard. Saying that S-100 will replace S-57 is not corrects, over S100 will be based a specific Product Specification (PS) called S-101 that will replace the standard currently used. S-101 is just one of the possible applications of S-100, other applications may include Bathymetric Surface (S-102), Under Keel Clearance Management (S-129), Traffic Management (S-127), Surface Currents (S-111), Radio Services (S-123), Water level Information for Surface Navigation (S-104) and etc.
\end{abstract}

S-100 will guarantee not only the management of not homogeneous type of data through standardized procedures, but also a wider usage of hydrographic data by different type of stakeholders. Hydrographic Offices around the world during the decades have collected many data with their institutional activities, currently this information are only used by a restricted user basin for limited applications and by limited stakeholders. Today, the importance of data is widely recognized and according to recent studies, a 3 trillion dollars value can be unlocked through a better usage and share of maritime data. The new standard gives the possibility to share data that today are only used by Hydrographic Offices and make it available for not-hydro type stakeholders. Having maritime data processed through standardize procedure will guarantee a certain level of interoperability between not homogeneous type of data and the production of new useful information. The combination of a multiplicity of data will guarantee a higher awareness of the operations carried out at sea and will guarantee higher level of efficiency. Multiple combination of data will permit the mariner to have access to new information from which the whole maritime community may benefit. It is not a matter of new data, the concept is about data that the community already have and it just needs to be merged together in order to fully develop its potential.

The ocean and sea surface is a complementary infrastructure to land facilities; the usage of this infrastructure requires the adoption of data collected and analysed by Hydrographic Offices. If the ocean is intended to be the "hardware", nautical charts can be intended as the "software" needed in order to use the hardware. In particular, nautical charts allow to merge and put together the hydro data collected and, most important they give the mariner a usable human readable information. If the connection between two shore-based points needs investments in physical infrastructures like highways, an arc between two sea based point, needs to be supported by a certain number of information. Having different data processed in a standard way can allow a more conscious usage of the ocean infrastructure and the application of some cartographic practices into other maritime related fields. 